\title{
EFEITOS DA SECA DE 2012 A 2016 NA QUALIDADE DA ÁGUA NOS AÇUDES ESTRATÉGICOS DA BACIA DO BANABUIÚ - CEARÁ
}

\author{
MARThA UChÔA ABREU ${ }^{1}$ \\ ${ }^{1}$ Instituto Federal de Educação, Ciência e Tecnologia do Ceará - IFCE \\ <martha_edna_@hotmail.com> \\ DOI: $10.21439 /$ conexoes.v15i0.1587
}

\begin{abstract}
Resumo. O uso intenso dos recursos hídricos devido ao aumento nos padrões de consumo e crescimento populacional compromete o equilíbrio e a manutenção da qualidade e quantidade da água. Nesse contexto, o Nordeste Brasileiro apresenta diversas dificuldades na gestão dos recursos hídricos por estar localizado em uma região de escassez hídrica, particularmente em períodos de seca como a ocorrida no período de 2012 a 2017 no Estado do Ceará, que afetam quali-quantitativamente as águas armazenadas em reservatórios superficiais. O presente trabalho teve como principal objetivo avaliar os efeitos da seca de 2012 a 2017 na qualidade da água de açudes estratégicos da bacia do Banabuiú, buscando analisar os dados de qualidade oriundos do monitoramento da Companhia de Gestão de Recursos Hídricos do Ceará (Cogerh). A partir de correlações de variáveis qualitativas, como Índice de Estado Trófico (IET), Cianobactérias e Fósforo, com o volume de água acumulado, constatou-se que quando os açudes estão com maiores volumes armazenados eles tendem a apresentar menores valores do IET. Conclui-se ainda que com a correlação dos açudes com menos de $20 \%$ do volume acumulado e o estado trófico no período de 2008 a 2017, verificou-se que a seca de 2012 a 2017 trouxe implicações na qualidade da água, visto que após esse período, 60\% a 80\% dos açudes passaram a estar com menos de $20 \%$ do volume acumulado, e todos os açudes com dados disponíveis estavam em estados eutrófico ou hipereutrófico.
\end{abstract}

Palavras-chaves: Eutrofização. Índice Trófico. Estiagem. Reservatórios. Semiárido.

\section{EFFECTS OF DROUGHT FROM 2012 TO 2017 ON THE WATER QUALITY IN THE STRATEGIC RESERVOIRS OF THE BANABUIÚ BASIN - CEARÁ}

\begin{abstract}
The intense use of water resources due to the increase in consumption patterns and population growth compromises the balance and maintenance of water quality and quantity. In this context, the Brazilian Northeast presents several difficulties in the management of water resources because it is located in a water scarce environment, particularly in periods of drought such as that occurred from 2012 to 2017 in the State of Ceará, which affect the quantity and quality of water stored in surface reservoirs. The main objective of this study was to assess the effects of the drought from 2012 to 2017 on the water quality of the strategic reservoirs in the Banabuiú basin, by analyzing the water quality data from the monitoring of the Water Resources Management Company of Ceará - COGERH. From correlations of qualitative variables, such as IET (Trophic State Index), Cyanobacteria and Phosphorus, with the volume of water accumulated, it was found that when the reservoirs present higher stored volumes they tend to present lower IET values. It is also concluded that with the correlation of the reservoirs with less than $20 \%$ of the accumulated volume and the trophic state in the period from 2008 to 2017, it was verified that the drought of 2012 to 2017 had implications in the quality of the water, since after this, $60 \%$ to $80 \%$ of the reservoirs presented less than $20 \%$ of the accumulated volume, and all reservoirs with data available were in eutrophic or hypereutrophic states.
\end{abstract}

Keywords: Eutrophication. Trophy Index. Drought. Reservoirs. Semiarid.

\section{INTRODUÇÃO}

A sustentabilidade dos recursos hídricos vem sendo amplamente discutida com a finalidade de buscar soluções e propostas para sua melhoria e conservação, em razão de ser um recurso limitado e essencial para diversos fins, principalmente abastecimento humano, irrigação, indústrias, entre outros. $\mathrm{O}$ acelerado processo de desenvolvimento urbano provocou mudanças tanto sociais, quanto ambientais, que alteraram o ciclo hidrológico, o escoamento dos rios e a qualidade do solo e da água (ARAúJO, 2012). O descontrolado processo de urbanização, a má disposição dos resíduos sólidos, deficiência no sistema de saneamento e manejo inadequado do solo contribui para o desequilíbrio dos recursos hídricos, que são intensamente utilizados, comprometendo tanto a qualidade quanto a quantidade da água (TUCCI, 2008). 
O Nordeste semiárido do Brasil aponta diversas dificuldades no âmbito hídrico. Suas características naturais, como precipitações irregulares e altas taxas de evaporação potencial, contribuem para que haja grande variação entre os períodos secos e chuvosos (REBOUÇAS 1997). Igualmente, a baixa umidade, as elevadas temperaturas e a predominância de solos rasos sobre substrato cristalino afetam ainda mais essa região semiárida (SOUZA; ARTIGAS; LIMA. 2015). Além dessas condições desfavoráveis, as ações antrópicas impactam negativamente a disponibilidade hídrica quantitativamente e qualitativamente. Com essa associação de fatores, o processo de eutrofização de mananciais se intensifica.

Mendes et al. (2012), por exemplo, expõem que vários elementos podem influenciar o estado de trofia do açude Banabuiú. Além das condições naturais em que está inserido, o uso e ocupação da bacia hidrográfica, o lançamento de cargas poluidoras, entre outras, são fatores preponderantes para se entender o nível trófico de um corpo hídrico.

A eutrofização se dá com o aumento dos nutrientes como fósforo e nitrogênio nos corpos d'água, e faz promovendo o aumento da produtividade de macrófitas aquáticas e algas (ESTEVES, 1998). O processo é natural e lento, podendo ser fortemente intensificado com as ações antrópicas que afetam a qualidade e disponibilidade da água para seus diversos usos, inclusive o abastecimento humano.

A eutrofização é um problema que ocorre em vários corpos d'água localizados no mundo todo, principalmente nos países em desenvolvimento, mas não é algo exclusivo desses países. Na Europa, grande parte dos lagos, lagoas e reservatórios artificiais estão em um estado considerado avançado de eutrofização. Como por exemplo, na Espanha, em que 30\% dos açudes encontram-se eutrofizados e nas lagoas açorianas de Portugal também (EXPLICATORUIM, 2018).

Segundo Lima (2012), o processo de eutrofização é favorecido pelo envelhecimento do corpo hídrico, sendo derivado principalmente da irregularidade e escassez hídrica que ocasiona a não renovação das águas, elevando os níveis tróficos dos reservatórios.

Dados do Portal Hidrológico da Secretaria de Recursos Hídricos do Ceará (SRH) mostraram que no final de 2017, 81,7\% dos açudes monitorados no estado encontravam-se eutrofizados ou hipereutrofizados e somente $18,2 \%$ dos açudes tinham níveis mesotróficos ou oligotróficos.

Os açudes assumem uma dinâmica temporal com relação ao nível trófico, em que por momentos assumem comportamentos hipereutróficos e por outros me- sotróficos ou até mesmo oligotróficos. Como exemplo, pode-se citar o açude São José I, situado na bacia do Banabuiú, que no início do ano de 2009 encontrava-se hipereutrofizado, porém em meados de 2009, ano em que houve grande quantidade de chuva em todo o estado, evidenciou comportamento mesotrófico até início de 2012, e posteriormente admitiu nível eutrofizado até final de 2017.

No período de 2012 a 2017 o estado do Ceará enfrentou uma das maiores secas de sua história, e ao final desse período praticamente todos os municípios inseridos na bacia do Banabuiú estavam em situação de emergência devido à seca (Figura 1).

Figura 1: Mapa do Ceará com indicação dos municípios em situação de emergência por seca.

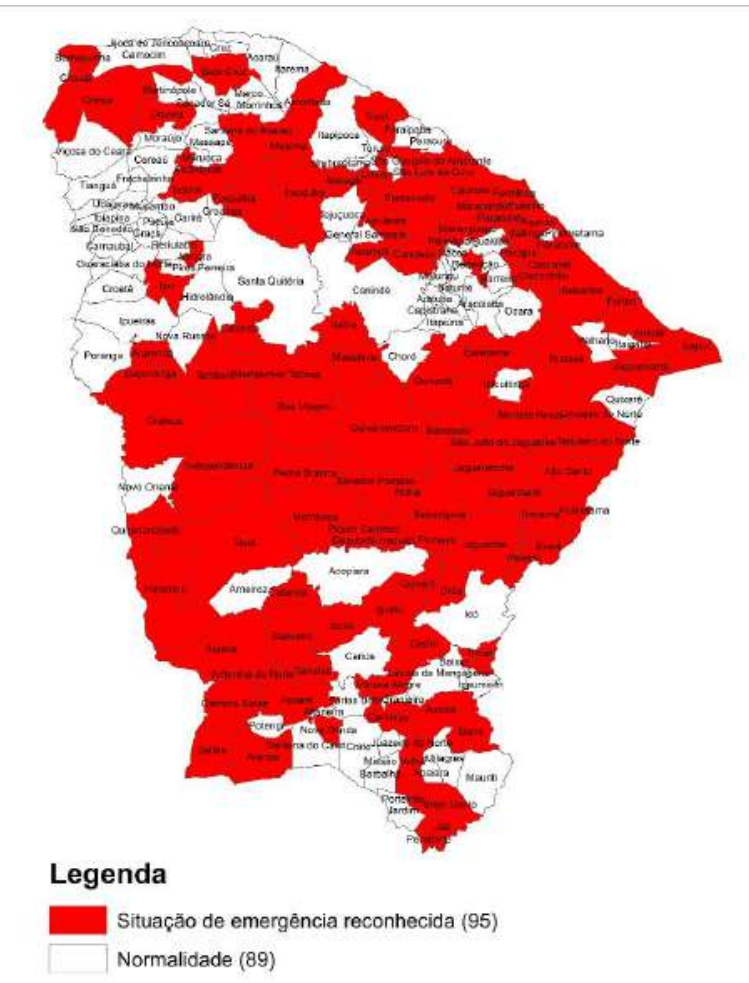

FONTE: Coordenadoria Estadual de Defesa Civil, atualizado em 29/12/2017

Diante desse contexto, o presente trabalho objetivou avaliar os efeitos da seca de 2012 a 2017 na qualidade da água de açudes estratégicos da bacia do Banabuiú, buscando analisar os dados de qualidade oriundos do monitoramento da Companhia de Gestão de Recursos Hídricos do Ceará - COGERH, quantificar o IET (Índice de Estado Trófico) de cada açude e sua relação temporal com a dinâmica hidrológica da bacia e o tempo de residência da água, a fim de contribuir com a gestão dos 
recursos hídricos.

\section{METODOLOGIA}

\section{1 Área do estudo}

A bacia do Banabuiú está localizada no Sertão Central do Estado do Ceará, região mais fortemente submetida aos rigores da semiaridez. Por sua localização central (Figura 2), limita-se com quase todas as bacias do estado, exceto as bacias do Coreaú, do Litoral e a do Salgado. A área drenada pela bacia é de $19.810 \mathrm{~km}^{2}$, o rio Banabuiú desenvolve-se no sentido oeste-leste, percorre um curso total de $314 \mathrm{~km}$, até desaguar no rio Jaguaribe nas proximidades da cidade de Limoeiro do Norte. Sua área equivale a $13 \%$ do território cearense (CEARÁ, 2009).

Figura 2: Mapa da bacia hidrográfica do Banabuiú.

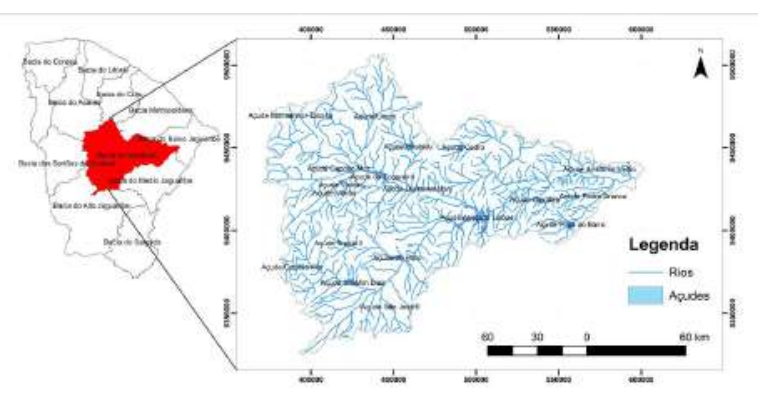

FONTE: Atlas SRH

A bacia do Banabuiú recebe contribuição de $12 \mathrm{mu}$ nicípios que dispõem de 19 açudes monitorados pela COGERH: Banabuiú, Capitão Mor, Cedro Cipoada, Curral Velho, Fogareiro, Jatobá, Monsenhor Tabosa, Patu, Pedras Brancas, Pirabibu, Poço do Barro, Quixeramobim, São José I, São José II, Serafim Dias, Trapiá II, Umari e Vieirão. Juntos, esses açudes possuem capacidade de acumulação de aproximadamente 2,8 bilhões de $\mathrm{m}^{3}$ (Tabela 1 ).

A região em que a bacia está inserida apresenta clima tropical quente semiárido, regime de chuva irregular e déficit hídrico, com temperaturas anuais médias em torno dos $26^{\circ}$ a $28^{\circ} \mathrm{C}$. A precipitação média anual é aproximadamente 725,4 $\mathrm{mm}$ (INMET, 2017).

Do ponto de vista geológico, a bacia do Banabuiú apresenta predominância de rochas do embasamento cristalino, recoberto por solos rasos como argissolos, luvissolos, neossolos, chernossolos, vertissolos e planossolos que têm maior distribuição nessa área, sobre os quais se desenvolve a típica vegetação de caatinga arbustiva, em manchas mais ou menos densas (COGERH 2017).
De acordo com o último censo demográfico do IBGE de 2010, os municípios da bacia possuiam 422.724 habitantes com pouco mais da metade da população residindo na zona urbana e a outra parte na zona rural e apresenta acentuado crescimento populacional, exceto Senador Pompeu e Ibicuitinga que tiveram decréscimo populacional. Conforme o levantamento realizado pelas gerências regionais da COGERH, os principais usos dos recursos hídricos no entorno da bacia são para: dessedentação animal, uso doméstico, uso público (empresas concessionárias), irrigação, pesca artesanal, agricultura de vazante, balneário e piscicultura intensiva (criação em gaiolas).

A disponibilidade hídrica é considerada boa, quando comparada com a de outras regiões do sertão cearense, principalmente depois da instalação de uma válvula no açude Arrojado Lisboa (açude Banabuiú), que libera uma vazão necessária para perenização do rio Banabuiú. Desta forma, é possível a exploração dos recursos hídricos com finalidades pecuárias e de irrigação das lavouras. As principais atividades agropecuárias são rebanhos bovino, caprino e ovino e as principais culturas agrícolas são, arroz, milho e feijão.

A bacia possui notável déficit hídrico atmosférico para todos os municípios nela inseridos. Isso se deve às elevadas temperaturas e altas taxas de evaporação potencial, aliadas às fracas pluviosidades, desta forma, o escoamento na rede de drenagem natural fica praticamente restrito aos períodos chuvosos.

O gráfico (Figura 3) apresenta o volume de água acumulado no açude Banabuiú durante o período de 2004 até 2017, comparando com a capacidade de acumulação. Pode-se observar que do ano de 2009 até 2012 o açude passou a acumular água, resultado de grandes médias pluviométricas no ano de 2009 em todo o estado, incluindo a bacia do Banabuiú, o que propiciou nos anos seguintes o aumento do volume. Já a partir de 2012 até 2017, observou-se uma queda em relação a esse volume, isso se deu pelos baixos índices de chuva durante esse período, que gerou redução do volume não só no açude Banabuiú, mas também em outros açudes de menor porte da região, como é o caso também de Monsenhor Tabosa (Figura 4).

Devido à variação sazonal das chuvas na região, em quem os primeiros meses do ano (janeiro-junho) são chuvosos e os últimos (julho-dezembro) são secos, os reservatórios em sua grande maioria são interanuais, pois são capazes de armazenar toda água do período chuvoso e guardar parte desses volumes para os anos seguidos. 
Tabela 1: Capacidade de acumulação dos açudes estratégicos da bacia do Banabuiú.

\begin{tabular}{lllr}
\hline \multicolumn{1}{c}{ Municípios } & \multicolumn{1}{c}{ Açude } & \multicolumn{1}{c}{$\begin{array}{c}\text { Comportamento geral } \\
\text { (IET) }\end{array}$} & $\begin{array}{r}\text { Capacidade de Acumulação } \\
\left(\mathbf{h m}^{\mathbf{3}}\right)\end{array}$ \\
\hline Banabuiú & Banabuiú & Eutrófica & 1601 \\
Pedra Branca & Capitão mor & Eutrófica & 6 \\
Quixadá & Cedro & Hiperotrófica & 126 \\
Morada Nova & Cipoada & Eutro/Hiper & 86 \\
Morada Nova & Curral Velho & Eutrófica & 12 \\
Quixeramobim & Fogareiro & Eutrófica & 119 \\
Milhã & Jatobá & Mesotrópica & 1 \\
Mosenhor Tabosa & Mosenhor Tabosa & Hiperotrófica & 12 \\
Senador Pompeu & Patu & Eutro/Hiper & 72 \\
Quixadá & Pedras Brancas & Eutrófica & 434 \\
Quixeramobim & Pirabibu & Hiperotrófica & 74 \\
Morada Nova & Poço do Barro & Eutrófica & 52 \\
Quixeramobim & Quixeramobim & Eutrófica & 8 \\
Boa Viagem & São José I & Mesotrópica & 8 \\
Piquet Carneiro & São José II & Eutrófica & 29 \\
Mombaça & Serafim Dias & Eutro/Hiper & 43 \\
Pedra Branca & Trapiá II & Eutrófica & 18 \\
Madalena & Umari & Eutrófica & 35 \\
Boa Viagem & Vieirão & Hiperotrófica & 21 \\
\hline Total & 19 açude & & $\mathbf{2 7 5 7}$ \\
\hline
\end{tabular}

Figura 3: Volumes de água acumulados no açude Banabuiú - 2004 a 2017.

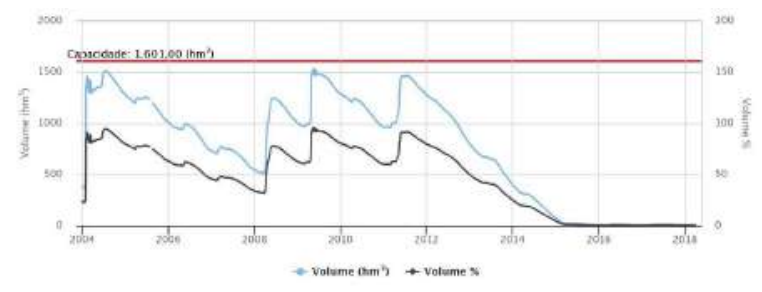

FONTE: COGERH 2017

Figura 4: Volumes de água acumulados no açude Mosenhor Tabosa - 2004 a 2017.

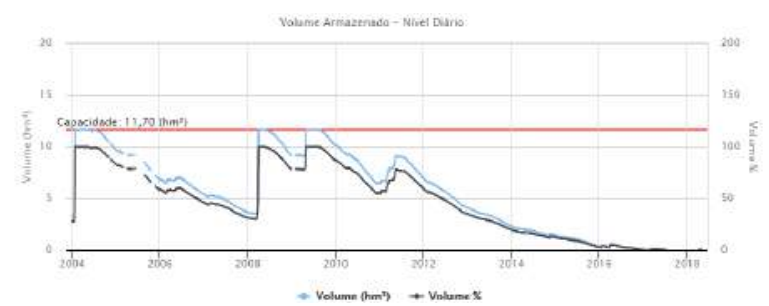

FONTE: COGERH 2017

\subsection{Avaliação da qualidade da água na bacia do Banabuiú}

A eutrofização é um processo gradativo que resulta do aumento das concentrações de nutrientes no corpo hídrico, que são principalmente o fósforo e o nitrogênio, além de provocar a proliferação de cianobactérias devido ao surgimento de plantas aquáticas. Nesse contexto, os parâmetros utilizados para quantificar e analisar o nível trófico no estudo foi fósforo total, que tem sido apontado como nutriente limitante em corpos hídricos continentais.

O Índice de Estado Trófico (IET) tem como objetivo classificar os corpos d'água segundo o grau de trofia (Tabela 3), permitindo a avaliação da qualidade da água (CETESB, 2007).

Para o cálculo do nível trófico de cada açude, a fim de avaliar sua variabilidade temporal, foi aplicada a equação de Lamparelli (2004) para reservatórios, que utiliza como parâmetro o fósforo total e é representada pela seguinte equação:

$$
I E T=10 \times(6-(1,77-0,42 \times(\ln P T) / \ln 2))
$$

onde o fósforo total (PT) é expresso em $\mu g / L$. 


\begin{tabular}{|c|c|}
\hline \multicolumn{2}{|c|}{ Tabela 2: Estado de Trofia e significado } \\
\hline Grau de Trofia & Significado \\
\hline Oligotrofico & $\begin{array}{l}\text { Possuem águas limpas, de baixa } \\
\text { produtividade, em que nāo ocorrem } \\
\text { interferências indesejáveis sobre os usos da } \\
\text { água, decorrentes da presença de nutrientes. }\end{array}$ \\
\hline Mesotrófico & $\begin{array}{l}\text { Sāo águas com produtividade intermediária, } \\
\text { com possiveis implicaçōes sobre a qualidade } \\
\text { da água, mas em niveis aceitáveis, na } \\
\text { maioria dos casos. }\end{array}$ \\
\hline Eutrófico & $\begin{array}{l}\text { Sāo os corpos de água com alta } \\
\text { produtividade, com redução da trans parência, } \\
\text { em geral afetados por atividades antrópicas, } \\
\text { nos quais ocorrem alteraçōes indes ejáveis na } \\
\text { qualidade da água e interferências nos usos } \\
\text { múltiplos }\end{array}$ \\
\hline Hipereutmofico & $\begin{array}{l}\text { Águas afetadas significativamente pelas } \\
\text { elevadas concentraçōes de matéria orgânica } \\
\text { e nutriente, com comprometimento } \\
\text { acentuado nos seus usos, associado a } \\
\text { episódios de floraçóes de algas ou } \\
\text { mortandade de peixes, com } \\
\text { comprometimento acentuado nos seus usos. }\end{array}$ \\
\hline
\end{tabular}

FONTE: Adaptado de Brasil (2009)

$$
\operatorname{IET}(C L)=10 \times(6-((0,92-0,34 \times(\ln C L)) / \ln 2))
$$

onde a clorofila a $(C L)$ é expressa em $\mu g / L$.

$$
\operatorname{IET}(C L)=10 \times(6-((\ln S)) / \ln 2))
$$

onde a transparência $(S)$ é expressa em $m$.

O IET representa a média aritmética simples dos índices envolvidos. Normalmente não se consideram o índice de transparência, uma vez que ele é afetado pelo material em suspensão o que pode ser comum em alguns reservatórios e que também pode caracterizar poluição.

Como forma de identificar algum padrão de nível trófico com as características hidrológicas dos açudes, buscou-se correlacionar o IET com o tempo de residência da água nos açudes, expresso pela equação:

$$
T R=\frac{C_{A}}{V_{M}}
$$

Em que: $C_{A}$ é a Capacidade de acumulação $\left(\mathrm{m}^{3}\right)$ e $V_{M}$ é o Volume médio afluente anual $\left(\mathrm{m}^{3} / \mathrm{ano}\right)$.

Os dados utilizados para o presente estudo foram obtidos da COGERH (Companhia de Gestão de Recursos Hídricos do Ceará), que é responsável pelo monitoramento quali-quantitativo dos açudes do estado. As informações disponibilizadas foram os parâmetros de qualidade, que são as concentrações de fósforo total, nitrogênio, clorofila, cianobactérias, transparência, e o nível trófico de cada açude. As campanhas do referido monitoramento se estenderam do período de fevereiro de 2008 a novembro de 2017 , totalizando 40 campanhas.

Os dados de cada açude foram obtidos da seguinte forma: a área e a capacidade de acumulação foram colhidos da ficha técnica da Secretaria de Recursos Hídricos do Ceará - SRH; a lâmina de escoamento anual foi obtida do trabalho de Nascimento e Medeiros (2017); o volume médio afluente anual como produto da lâmina de escoamento (mm/ano) com a área $\left(\mathrm{m}^{2}\right)$ da bacia. As séries de volumes acumulados nos açudes foram obtidas do Portal Hidrológico do Ceará.

Para avaliar a influência da dinâmica hidrológica da bacia sobre a qualidade da água nos açudes, as variáveis de qualidade de água foram comparadas com os volumes acumulados nos açudes ao longo do período de estudo. Para cada açude em particular foram elaborados três gráficos do mesmo modo, desprezando as falhas nos registros, que correlacionam as variáveis de qualidade (IET, concentrações de fósforo total e cianobactérias) com o volume acumulado.

\section{RESULTADOS E DISCUSSÕES}

\subsection{Variabilidade da qualidade da água de acordo com o tempo de residência dos reservatórios}

Apesar de os mananciais na bacia do Banabuiú não serem classificados de acordo com a resolução do Conselho Nacional do Meio Ambiente - CONAMA (CONAMA 357/2005), é importante que se compreenda a dinâmica temporal da qualidade da água para fins de comparação com o que estabelece a legislação.

Quanto ao tempo de residência, quanto menor, maior a tendência do reservatório se comportar como rio. Do contrário, com o aumento do tempo de residência, há tendência de grande parte de o reservatório apresentar padrões típicos de ambientes lacustres (MEIRINHO, 2010). Em reservatórios, por serem ambientes lênticos, apresentam tempo de residência maior, podendo gerar índices consideráveis de eutrofização.

A presença do fósforo nas águas se dá principalmente por lançamentos de esgotos domésticos, o qual é comum no entorno da bacia, pois contém detergentes superfosfatos e a própria matéria fecal. O uso de fertilizantes e agrotóxicos é intenso na bacia segundo a matriz dos impactos, já os efluentes da indústria alimentícia, frigoríficos e abatedouros influenciam nos valores de fósforo, porém são amenos quando relacionados às principais fontes já citadas. A Resolução do CONAMA 357/2005 estabelece como valor máximo permitido de 
fósforo total em ambientes lênticos de $0,020 \mathrm{mg} / \mathrm{L}$ para águas doces de classe I, $0,030 \mathrm{mg} / \mathrm{L}$ para ambientes lênticos de classe II e $0,050 \mathrm{mg} / \mathrm{L}$ para águas de classe III.

$\mathrm{Na}$ bacia, observou-se que a concentração de fósforo apresenta baixa correlação com o tempo de residência da água nos açudes, com grande dispersão dos valores principalmente para tempos de residência baixos (Figura 5).

Figura 5: Correlação da concentração de fósforo com o tempo de residência da água nos açudes na bacia do Banabuiú.

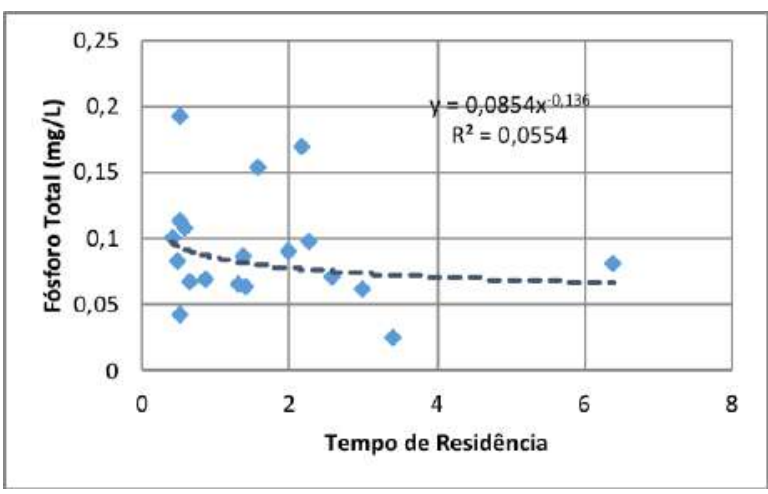

De maneira geral, o IET indica o nível trófico a partir do parâmetro de fósforo total, com isso, correlaciona-se com os usos e os efluentes descarregados no corpo hídrico, que causam impactos e modificações da composição natural daquele manancial e da bacia em geral. As atividades são diversas como efluentes domésticos, os compostos tóxicos lançados pelo uso de agrotóxicos e fertilizantes advindos das atividades da agricultura e as atividades pecuárias, principalmente com o acesso de animais às bacias hidráulicas dos açudes (Figura 6).

Na bacia do Banabuiú, o IET também não apresentou correlação significativa com o tempo de residência da água nos açudes, como indicado na Figura 7

A presença de algumas espécies de cianobactérias pode ter potencial tóxico, quando em altas quantidades, comprometendo a qualidade da água, restringindo seu uso e distribuição e até mesmo seu tratamento. Associado ao aumento de cianobactérias ocorre o aparecimento de algas que, por muitas vezes, provoca a mortandade de animais e danos à saúde humana. De acordo com a resolução CONAMA 357/2005, que dispõe sobre procedimentos e responsabilidades inerentes ao controle e à vigilância da qualidade da água para consumo humano, o número de cianobactérias na água de um manancial não deve exceder 50.000 células $/ \mathrm{mL}$. O gráfico de cianobactérias versus tempo de residência da água nos açudes da bacia do Banabuiú (Figura 8) mostrou grande amplitude da contagem de cianobacté-
Figura 6: Atividades observadas na bacia do Banabuiú que impactam a qualidade da água de açudes: cultivo de vazante, uso de agrotóxicos e animais acessando os açudes para dessedentação.

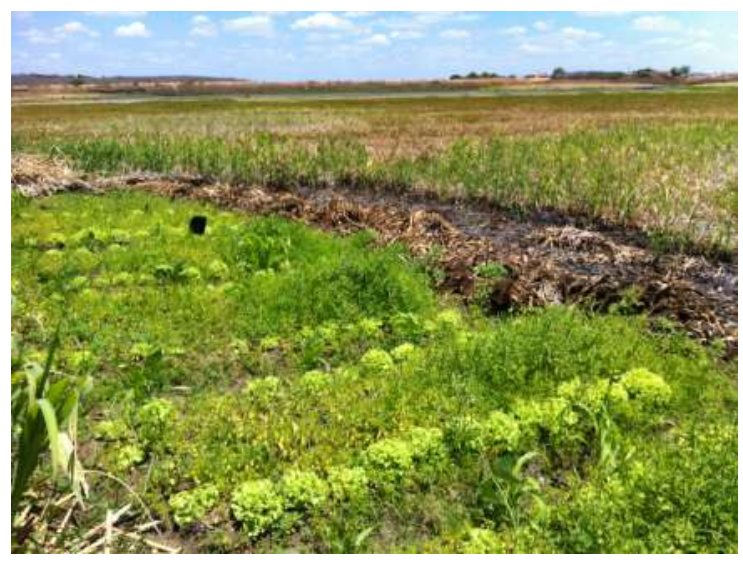

(a)

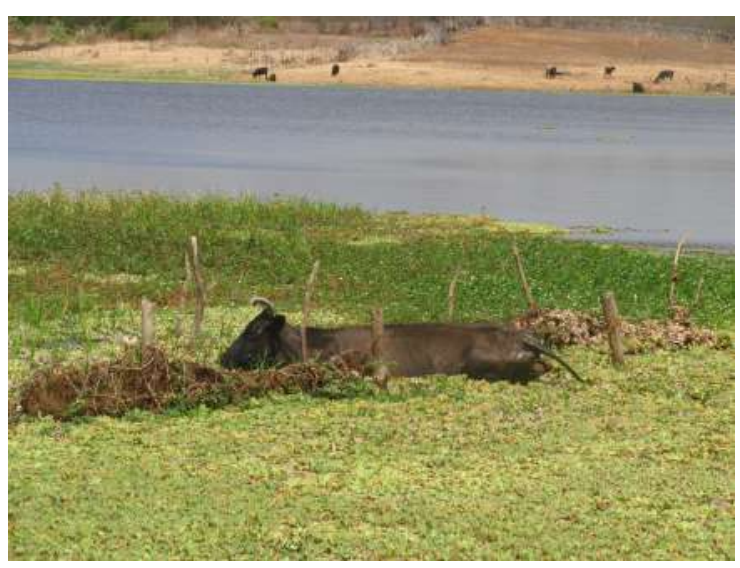

(b)

Figura 7: Correlação do IET com o tempo de residência da água nos açudes na bacia do Banabuiú.

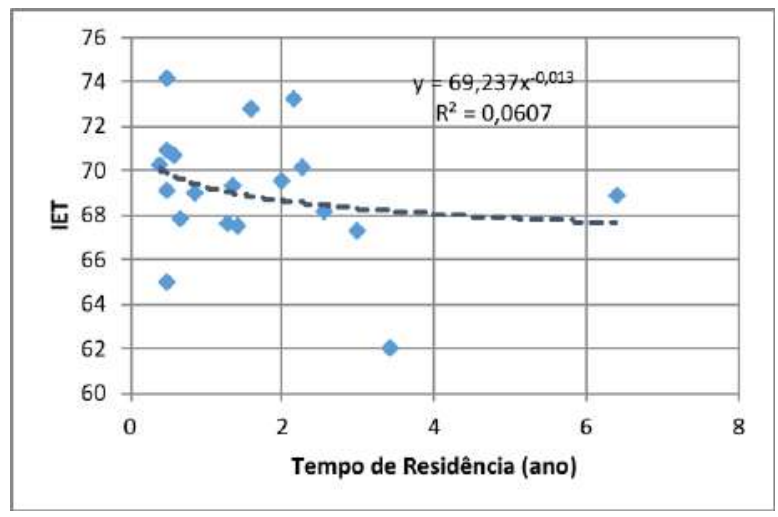

rias nos açudes estudados, também apresentando baixa correlação entre essas variáveis. 
Figura 8: Correlação do número de cianobactérias com o tempo de residência da água nos açudes na bacia do Banabuiú.

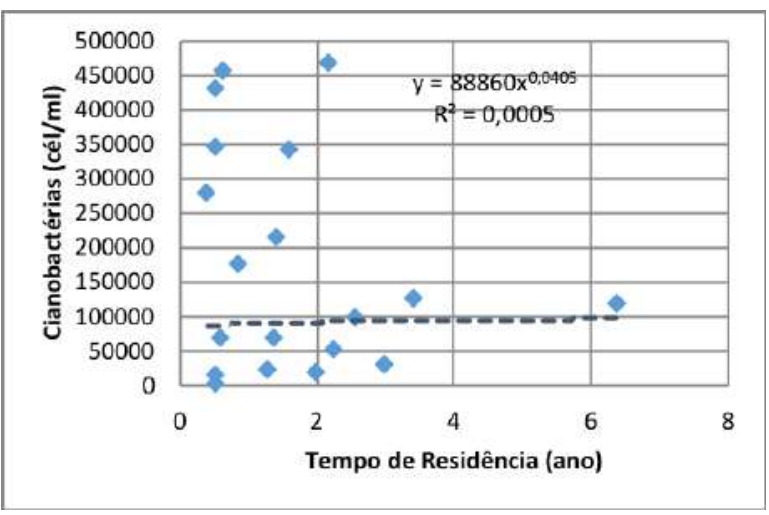

De acordo com a matriz dos principais impactos ambientais, disponibilizado pela COGERH, as principais fontes de nitrogênio na bacia, de um modo geral, são lançamentos de esgotos sanitários e efluentes industriais, e podem ocorrer nas formas de nitrogênio orgânico, amoniacal, nitrito e nitrato. O despejo excessivo de compostos de nitrogênio nos corpos hídricos propicia o crescimento descomedido das algas, o que pode afetar o abastecimento público, a recreação e a preservação da vida aquática (BUENO, 2011). A Resolução 357 do Conama de 2005 para águas doces de classes 1 e 2, estabelece quando o nitrogênio for fator limitante para eutrofização, nas condições estabelecidas pelo órgão ambiental competente, o valor de nitrogênio total (após oxidação) não deverá ultrapassar 1,27 mg/L para ambientes lênticos e 2,18 mg/L para ambientes lóticos, na vazão de referência. A Figura 9 apresenta o gráfico de concentração de nitrogênio versus o tempo de residência da água nos açudes, sendo possível observar mais uma vez a baixa correlação entre as variáveis.

A correlação entre os valores medianos das variáveis estudadas (nitrogênio, fósforo, cianobactérias e IET) e o tempo de residência da água no açude não é significativa, o que pode indicar que os valores medianos das variáveis não caracterizam fielmente o estado geral dos açudes, ou seja, provavelmente sua dinâmica temporal seja mais importante e relevante para expressar a qualidade da água dos açudes, tendo em vista a quantidade de água acumulada.

A Figura 10 apresenta o percentual de açudes com volume acumulado inferior a $20 \%$ no período de 2008 a 2017, sendo possível verificar a situação da bacia antes e durante período de seca de 2012 a 2017 . No início desse período até o ano de 2011, poucos açudes se encontravam escassos hidricamente, já no período da seca ou que sucede, é possível verificar que a maior
Figura 9: Correlação da concentração de nitrogênio com o tempo de residência na bacia do Banabuiú.

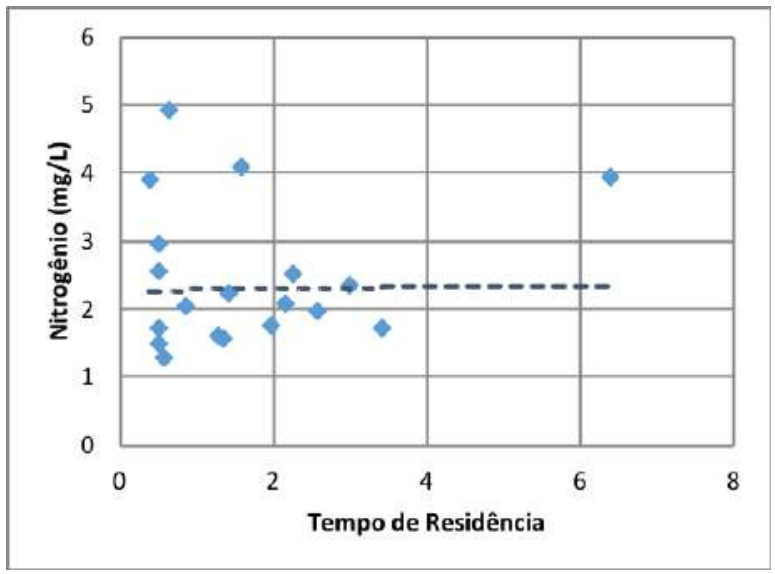

parte dos açudes estava com redução no seu volume, ou seja, com menos de $20 \%$ dele, especialmente nos últimos dois anos de dados (2016 e 2017).

Figura 10: Percentual de açudes com menos de $20 \%$ do volume acumulado no período de 2008 a 2017.

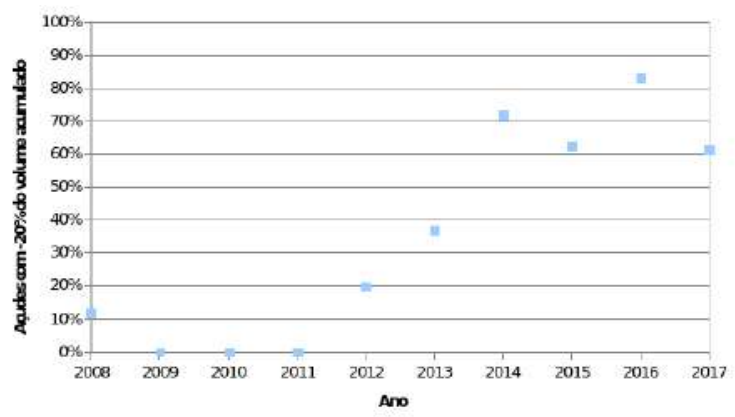

A Figura 11 mostra o percentual de açudes eutróficos ou hipereutróficos ao longo do período de monitoramento da qualidade da água (2008 a 2017), os quais possuíam melhor qualidade de um modo geral, visto que quase metade ainda estavam em situação oligotrófica ou mesotrófica. A partir de 2016, nenhum açude estava em níveis oligotróficos ou mesotróficos, isto é, $100 \%$ dos açudes estavam eutrofizados ou hipereutrofizados, devido à escassez hídrica da região decorrente da seca.

\subsection{Variabilidade da qualidade da água de acordo com o volume acumulado nos reservatórios}

Dentre os açudes estudados, alguns apresentam a mesma tendência visualmente como também no ajuste de curvas do tipo potência, em que o valor da variável IET aumenta muito para pequenos volumes e depois 
Figura 11: Percentual de açudes hipereutróficos e eutróficos no período de 2008 a 2017.

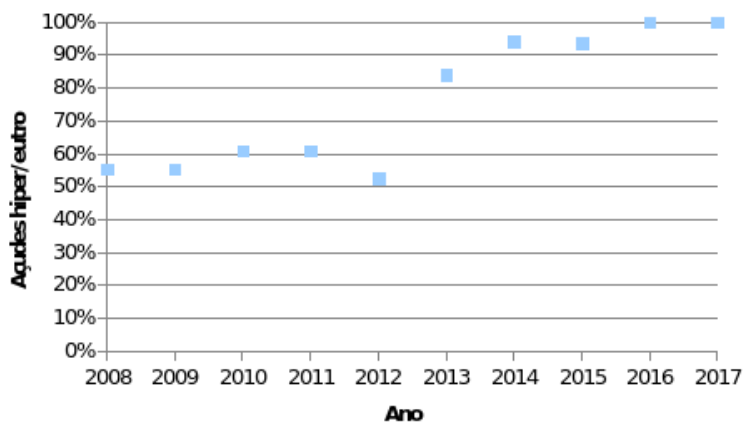

tende a estabilizar. O primeiro grupo de açudes (Figura 12 - Grupo 1) que possuem o mesmo comportamento foram os açudes Banabuiú, Fogareiro, Umari, Quixeramobim e Serafim Dias, em que o IET aparece quase como constante independente do volume acumulado, não tendo grandes variações no estado trófico quando correlacionado com o volume. Nesse grupo de açudes, é possível observar que quanto maior o volume acumulado, menores são os índices de trofia, mesmo que essa redução seja pequena.

O segundo grupo contém os açudes Patu, Trapiá II, Vieirão, Poço do Barro e Monsenhor Tabosa (Figura 13 - Grupo 2), que apresentam decrescimento visual mais significativo quando correlaciona-se o IET com o volume acumulado, sendo assim, quando há maiores volumes, o índice trófico tende a diminuir mais significativamente.

No grupo 3 (Figura 14 - Grupo 3), composto pelos açudes São José I e Jatobá, geralmente não possuem volumes acumulados tão baixos, tendo comportamento mesotrófico quase que ao longo de todo o período das campanhas realizadas. Nos gráficos, é possível verificar que os volumes não chegam a menos de $20 \%$ da capacidade de acumulação. A linha de tendência obedecida por esse grupo também mostra os índices tróficos diminuindo quando os açudes estão mais cheios.

Por fim, o quarto grupo (Figura 15- Grupo 4) com os açudes Cipoada, Pirabiru e São José II que de maneira geral apresentaram níveis eutro/hipereutróficos e diferentes do grupo 3 , nenhum chega a volumes acima de $80 \%$ ao longo dos anos de dados colhidos.

Os demais açudes não citados não seguiram uma tendência compatível com nenhum dos grupos citados, como no caso do açude Curral Velho (Figura 16- Curral Velho) que recebe água do açude Castanhão através do Eixão das Águas, portanto suas águas são misturadas com as daquele açude, não sendo observada tendência do IET com o volume acumulado.
Figura 12: Variação do IET de acordo com os volumes acumulados nos açudes na bacia do Banabuiú (Grupo 1)

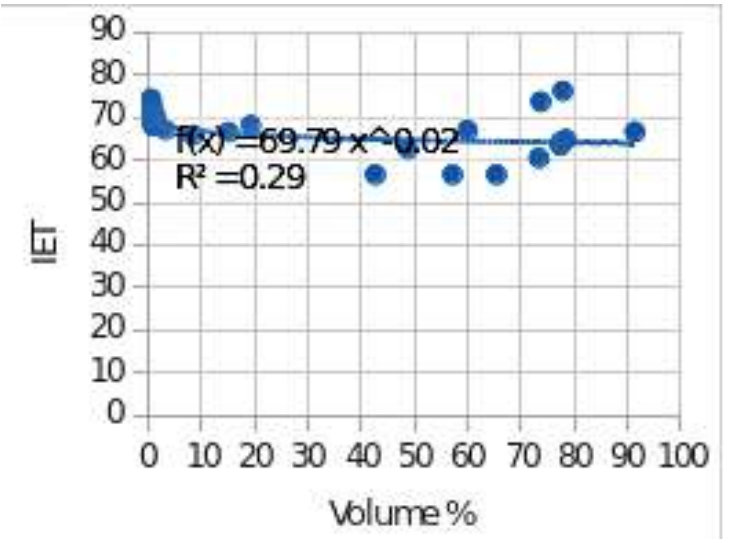

(a) Açude Banabuiú

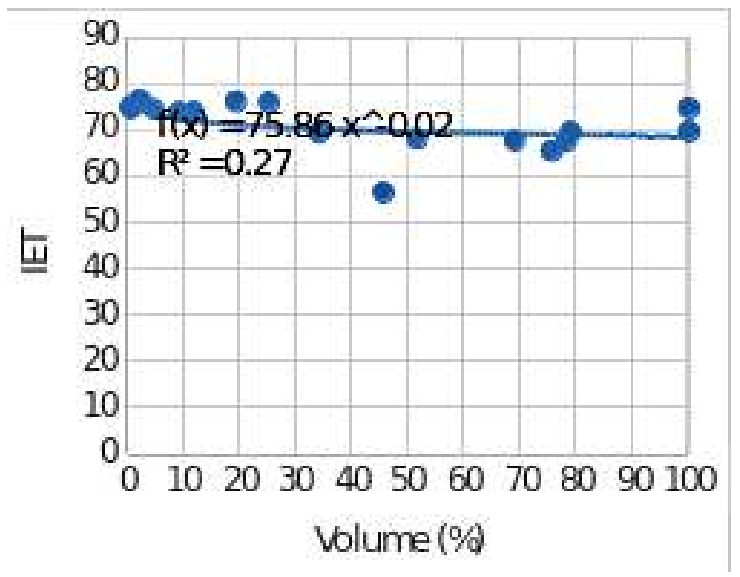

(b) Açude Fogareiro

\section{CONCLUSÕES}

A qualidade da água dos açudes estratégicos na Bacia do Banabuiú, analisada neste estudo através do índice de estado trófico, da contagem de cianobactérias e das concentrações de fósforo e nitrogênio, apresentou baixa correlação com o tempo de residência da água nos açudes, apesar de diversos estudos indicarem que a permanência da água em ambientes lênticos tende a promover o acúmulo de nutrientes / poluentes. Os resultados obtidos neste estudo indicam que os valores medianos adotados não representam satisfatoriamente a qualidade da água armazenada em açudes na região, que apresentam forte variabilidade temporal. O efeito da dinâmica hidrológica sobre a qualidade da água dos açudes estudados fica evidente quando se relaciona as variáveis de qualidade com os volumes acumulados ao longo do período de monitoramento, o que indica que 
Figura 13: Variação do IET de acordo com os volumes acumulados nos açudes na bacia do Banabuiú (Grupo 2)

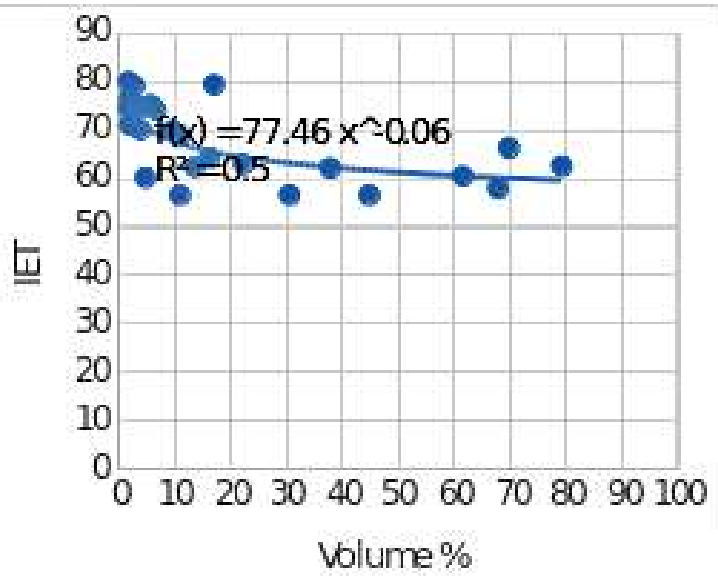

(a) Açude Poço Barro

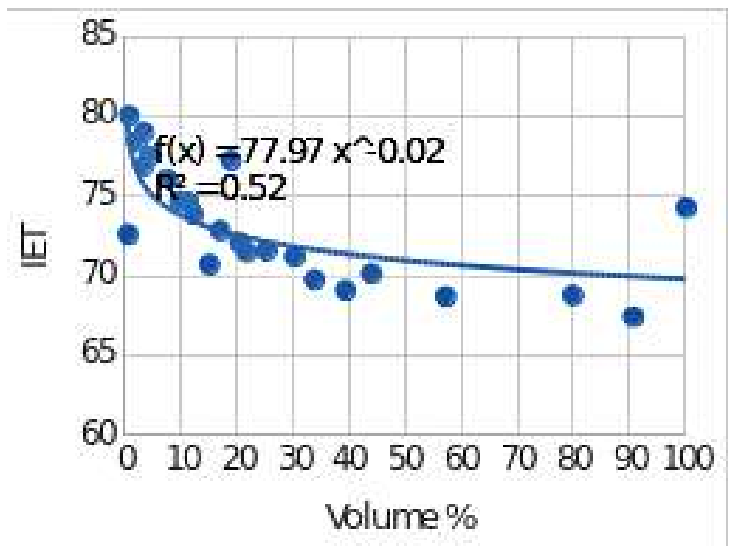

(b) Açude Monsenhor Tabosa

quando os açudes estão com maiores volumes armazenados tendem a apresentar menores valores do IET.

Conclui-se ainda que a seca de 2012 a 2017 trouxe implicações na qualidade da água na bacia do Banabuiú, visto que nos anos que antecedem esse período, a maior parte dos açudes (aproximadamente $80 \%$ do total) encontrava-se acima de $20 \%$ do seu volume acumulado e muitos (de $40 \%$ a $60 \%$ dos açudes) em níveis oligotróficos ou mesotróficos. Após esse período, principalmente nos últimos anos em que se perdurou a seca (2016 e 2017), 60\% a $80 \%$ dos açudes passou a estar com menos de $20 \%$ do volume acumulado, e todos os açudes com dados disponíveis estavam em estados eutrofizados ou hipereutrofizados.

\section{REFERÊNCIAS}

ARAúJO, L. H. S. d. Diagnóstico georreferenciado
Figura 14: Variação do IET de acordo com os volumes acumulados nos açudes na bacia do Banabuiú (Grupo 3)

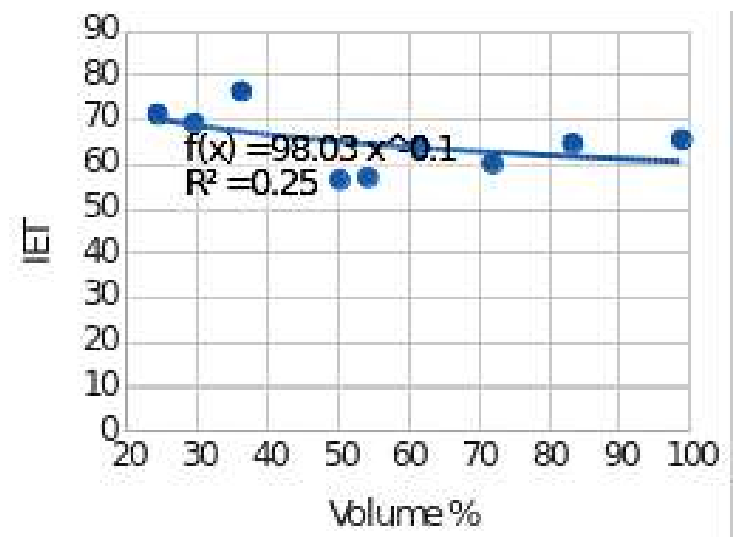

(a) Açude Jatobá

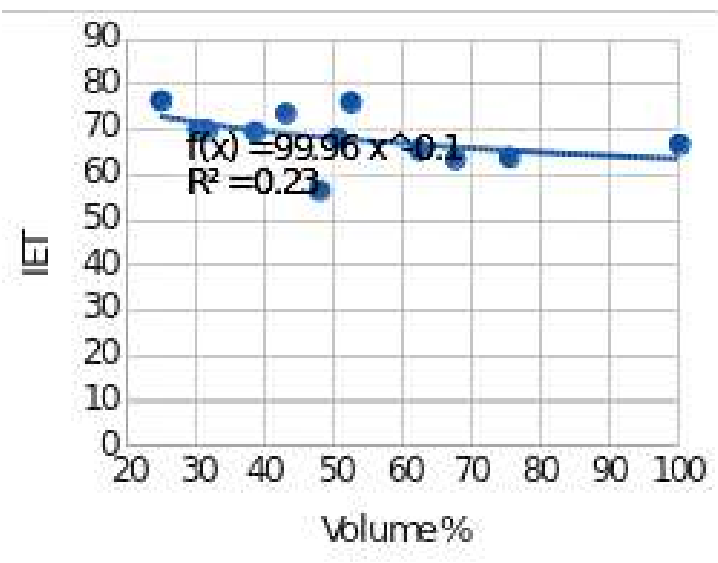

(b) Açude São José I

do uso e da ocupação do solo nas áreas de preservação permanente (APP) da sub-bacia B1, bacia do rio Cocó, Fortaleza-CE. Dissertação (Departamento de Engenharia Hidráulica e Ambiental) - Universidade Federal do Ceará - UFC, Fotaleza, 2012.

BRASIL. Indicadores de qualidade da água: índice de qualidade das águas. Brasília, 2009. Disponível em: <http://portalpnqa.ana.gov.br/ indicadores-indice-aguas.aspx $>$. Acesso em: 15 ago. 2017.

BUENO, R. F. Nitrificação e desnitrificação simultânea em reator com biomassa em suspensão e fluxo contínuo de esgoto. Dissertação (Pós-graduação em Saúde Pública) - Universidade de São Paulo USP, São Paulo, 2011. 
Figura 15: Variação do IET de acordo com os volumes acumulados nos açudes na bacia do Banabuiú (Grupo 4)

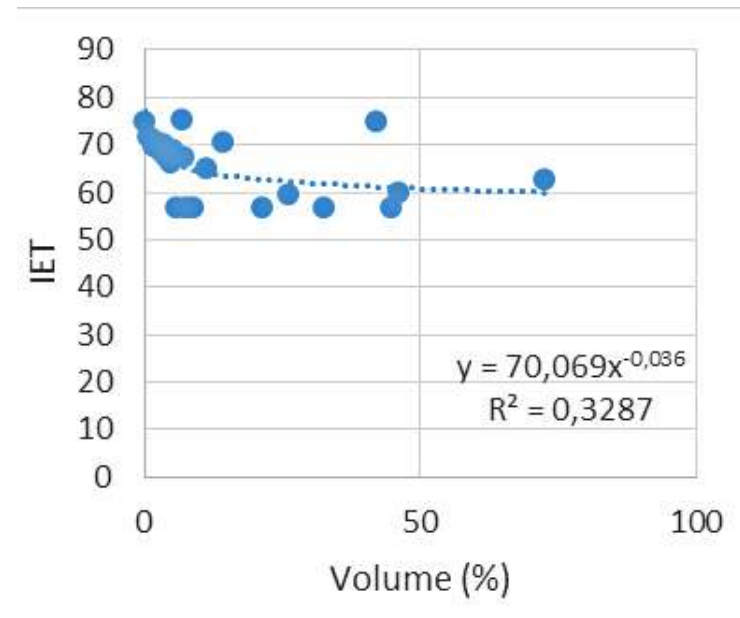

(a) Açude Cipoada

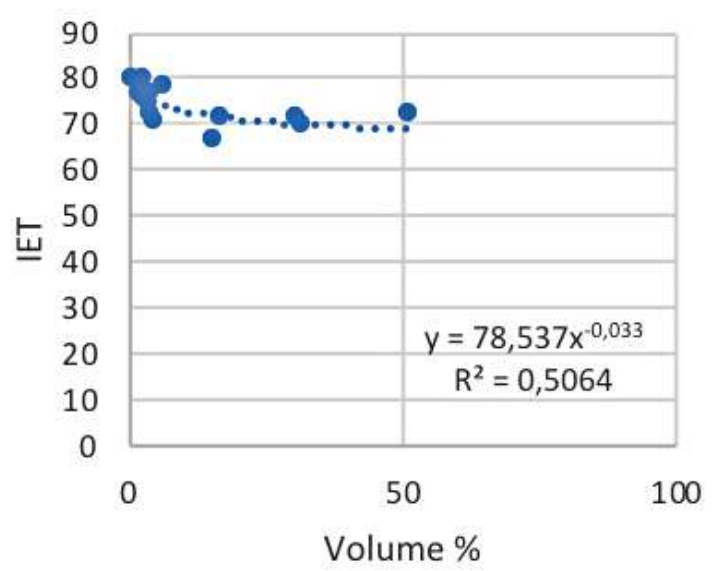

(b) Açude Pirabibu

CEARÁ. Caderno regional da sub-bacia do Banabuiú. Fortaleza, 2009. Disponível em: $<$ https://portal.cogerh.com.br/downloads/category/ 83-pacto-das-aguas-planoestrategico.html?download= 269:bacia-do-banabuiu> Acesso em: 09 mai. 2017.

CETESB. Qualidade das águas interiores no Estado de São Paulo - 2007. Companhia de Tecnologia de Saneamento Ambiental. São Paulo, 2007. Disponível em: <http: //www.cetesb.sp.gov.br/agua/rios/publicacoes.asp > Acesso em: 29 ago. 2017.

COGERH. Portal Hidrológico - Volume Armazenados dos Reservatórios. Fortaleza, 2017. Disponível em: $\langle$ http://www.hidro.ce.gov.br/> Acesso em: 15 jun. 2018.
ESTEVES, F. A. Fundamentos de limnologia. 2. ed. Rio de Janeiro: Interciência, 1998.

EXPLICATORUIM. Eutrofização, o que é e suas consequências. 2018. Disponível em: <http://www. explicatorium.com/sociedade/eutrofizacao.html $>$ Acesso em: 02 abr. 2018.

INMET. Tempo/Gráficos. Brasília, 2017.

LAMPARELLI, M. C. Grau de trofia em corpos d'água do estado de São Paulo: avaliação dos métodos de monitoramento. Tese (Departamento de Ecologia) - Universidade de São Paulo - USP, São Paulo, 2004.

LIMA, I. S. Caracterização física, química e biológica da água na sub-bacia B1, do Rio Cocó, Fortaleza-CE, com ênfase nos aspectos da poluição ao longo de um ciclo climático. Dissertação (Departamento de Engenharia Hidráulica e Ambiental) - Universidade Federal do Ceará - UFC, Fortaleza, 2012.

MEIRINHO, P. A. Compartimentalização da comunidade zooplanctônica em um reservatório urbano eutrofizados (Braço Rio Grande, Complexo Billings, SP). Dissertação (Instituto de Biociências) Universidade de São Paulo, São Paulo, 2010.

MENDES, D. L.; CUNHA, F. J.; ROLIM, H. d. O.; FERREIRA, L. L.; SOUZA, Y. J. D. de; OLIVEIRA, R. S. Avaliação do índice de estado trófico do açude banabuiú. In: VII CONNEPI-Congresso Norte Nordeste de Pesquisa e Inovação. [S.1.: s.n.], 2012.

NASCIMENTO, F. J. S. C.; MEDEIROS, P. H. A. Estudo de variabilidade temporal dos escoamentos como indicador do potencial de regularização de vazão através de açudes. Revista Water Resources and Irrigation Management, v. 6, n. 2, p. 115-129, 2017.

REBOUÇAS, A. d. C. Água na região nordeste: desperdício e escassez. Estudos avançados, SciELO Brasil, v. 11, n. 29, p. 127-154, 1997.

SOUZA, B. I. d.; ARTIGAS, R. C.; LIMA, E. R. V. d. Caatinga e desertificação. Mercator (Fortaleza), SciELO Brasil, v. 14, n. 1, p. 131-150, 2015.

TUCCI, C. E. M. Águas urbanas. Estudos avançados, SciELO Brasil, v. 22, n. 63, p. 97-112, 2008. 
Figura 16: Variação do IET de acordo com os volumes acumulados nos açudes na bacia do Banabuiú (Açudes com comportamentos distintos dos demais)

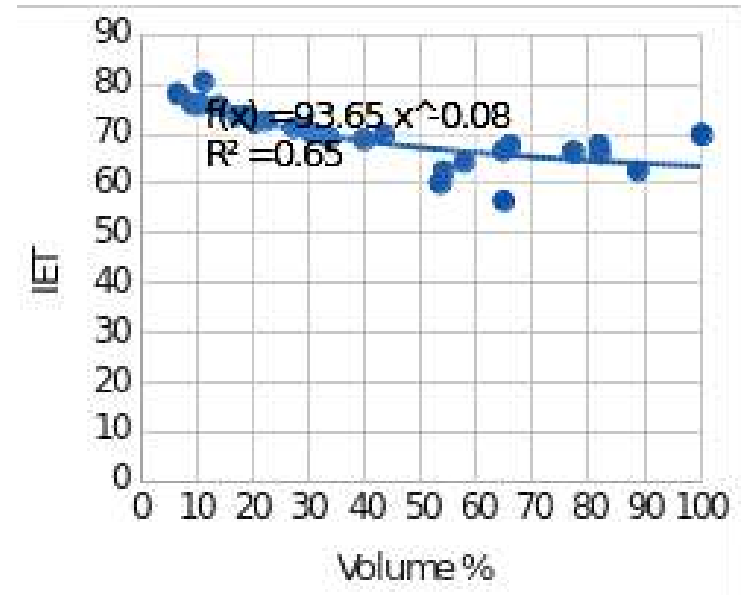

(a) Açude Capitão Mor

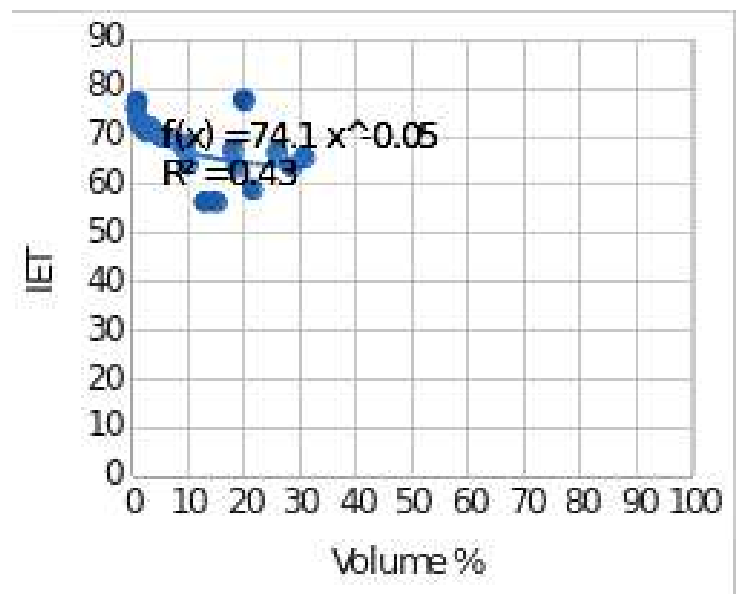

(b) Açude Cedro

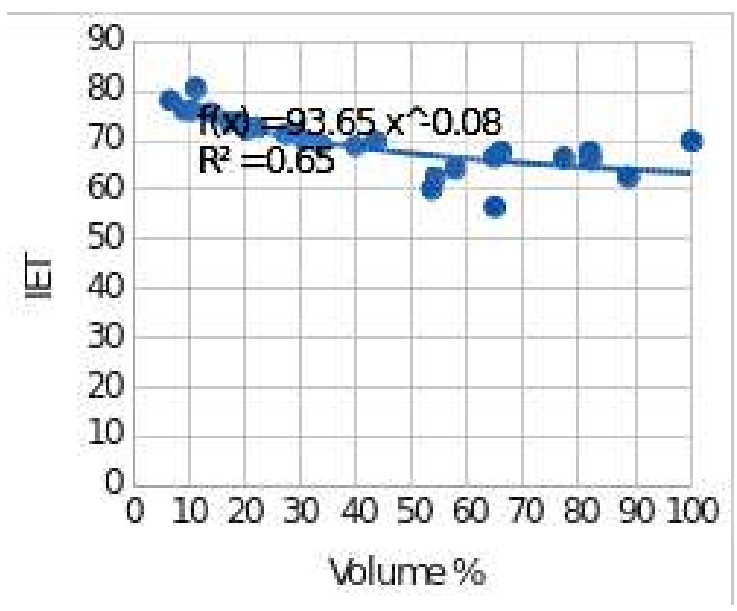

(c) Açude Curral Velho 